\title{
The perception of people with a physical disability towards those with a different kind of disability
}

\begin{abstract}
Monika Skura, The perception of people with a physical disability towards those with a different kind of disability. Interdisciplinary Contexts of Special Pedagogy, no. 26, Poznań 2019. Pp. 343-368. Adam Mickiewicz University Press. ISSN 2300391X. e-ISSN 2658-283X. DOI: https://doi.org/10.14746/ikps.2019.26.16
\end{abstract}

Difficulties resulting from the social perception of people with disabilities, and the personal assessment of their own disability are important for her/his relationship with other people. Therefore, it is worth asking what the perceptions are, of those who experience psychosocial effects due to their physical disability, towards people with intellectual disabilities, hearing impairments, visual impairments, mental illnesses, as well as their own physically disabled group. To analyse the perception of people with a physical disability, the study explores three areas: the acceptance or rejection of society's stigmatization towards persons with disabilities; integrative versus separative social orientations of people with physical disability; social preferences of people with physical disability regarding other disabled people. The research sample consisted of 75 people with physical disabilities, who suffer from damage to the locomotor system. The data was collected using a questionnaire The findings highlight that the response from those who were physically disabled agreed with the opinions of general society, not only with the issue of promoting integrated solutions and offering assistance, but also having the same preferences and opinions about specific types of disability. However, their perception regarding their own group was noticeably different from that of general society.

KEY WORDS: perception of disability, physical disability, society's opinions about disability, people with different kinds of disability 


\section{Introduction}

Social conventions, values, mechanisms of marking and qualifying differences in which, the so-called, full valued, impose their own norms of normality on a different person, determine the whole of their social relations. This is done due to the accepted and reproduced image, the attitude created, and the socially propagated attitude. Human cognitive structure in which the basic scheme of construction, appearance and functioning of the human body, affect the perception of those considered non-standard. Shaped by cultural factors and social model - a prototype of a human - define ideas, perceptions and social relations. Regardless of age, religion or political beliefs, standards that are most desirable and valuable in the hierarchy of our society are: health, attractiveness, strength, physical fitness, high intelligence and success. ${ }^{1}$

Assessing the clarity of certain external features, what is perceived as desirable and valuable, or what should be avoided, affects the quality of a relationship. In the meeting - human and I- physical characteristics, posture, gestures, clothing and other aspects are factors that cause attraction or repulsion of subjects. One's physical condition and appearance are particularly important in the modern world, in which the body extracted from private space, has become a cultivated product raised to the altars, omnipresent and perfect thanks to various kinds of efforts and treatments

Emotional tension caused by the dissimilarity of the other person may cause the perception of the individual as less valuable, imposing its own standards of assessment of the causes of disability,

${ }^{1}$ B.A. Wright, Developing constructive views of life with a disability. Rehabilitation Literature, 1980, 41(11-12), pp. 274-279; P. Schilder, The Image and Appearance of the Human Body, Kegan Paul, Trench, Trubner, London 1935; D. Umberson, M. Hughes, The Impact of Physical Attractiveness on Achievement and Psychological Well-Being, Social Psychology Quarterly, Social Psychology Quarterly 1987, Vol. 50, No. 3, pp. 227-236; M Hosod, G. Stone-Romero, G. Coats, The effects of physical attractiveness on job-related outcomes: a meta-analysis of experimental studies. Personnel Psychology 2006, Vol. 56, Issue 2, pp. 431-462. 
ways of functioning and adaptation. Attitude focused only on the relationship with what is known and typical may mean avoiding, rejecting and even questioning the co-creation of society by people perceived as different.

The attitude towards people with disabilities is also determined by the political, economic and social factors dependent on specific cultural conditions in which the participants of the relationship exist. Reproducing the stigmatizing assessment of the presence of people with disabilities as a "burden" threatening the community, may be manifested by indicating their non-productiveness, charging the costs of maintaining, caring for and protecting other people.

A particular difficulty in meeting a person with a disability is the presence of visible, severe disability or clearly disturbed behaviour. Stronger negative reactions are raised by the perception of a defect of significant external appearance, i.e. a meeting with a disfigured face, trunk deformities or whose appearance features indicate a mental disorder, intellectual disability or AIDS, someone who has lost sight or hearing, is ill with asthma, diabetes, cardiovascular and circulatory issues, or arthritis. ${ }^{2}$ Therefore, body injuries which are perceived in the first contact with a person with a disability are important, i.e. limitations in movement, communication, degree of independence and self-care, and the occurrence of social stigmatization of a given disability. ${ }^{3}$

Stereotypical perception and mechanisms of specific treatment of people with disabilities, which impose values, norms and imaginations on them, force them to accept the limitations resulting from the

${ }^{2}$ L. Gething, Generality vs. specificity of attitudes towards people with disabilities, British Journal of Medical Psychology, 1991, 64, pp. 55-64.

${ }^{3}$ L.M. Shears, C.J Jensema, Social acceptability of anomalous persons, "Exceptional Children" 1969, vol. 36, 91-96; E. Goffman, Stigma: Notes on Management of Spoiled Identity. Englewood Cliffs, New Jersey 1963; B.A. Wright, Developing constructive views of life with a disability. Rehabilitation Literature, 1980, 41(11-12), pp. 274-279; $\mathrm{R}$. Chubon, An analysis of research dealing with the attitudes of professionals toward disability. Journal of Rehabilitation, 1982, 48(1), pp. 25-30; M.E. MacLaughlin, M.P. Bell, D.Y. Stringer, Stigma and Acceptance of Persons With Disabilities. Group \& Organization Management, 2004, Vol. 29 No. 3, pp. 302-33. 
label given to them, stigmatizing names, categorization. All unusual, unconventional ways to perform various everyday activities are not met with understanding. A branding etiquette: disabled, handicapped or crippled, limits the perception of a person to a generalized image filled with social prejudices. A person with a disability is identified in the relationship as a "copy" of a given classification, and not as a unique individual. The attribution of the stigma deprives it of its positive qualities, gives it a label of the substance as a worthless, unnecessary member of society and involves such behaviour towards it as the restrictive name designates. Experience in quality direct interaction with people with disabilities and knowledge of their problems have been the subject of expertise carried out under the direction of Antonina Ostrowska ${ }^{4}$ with researchers from The Polish Academy of Sciences. The questions that were addressed to non-disabled respondents took into account the issues of proximity to people with disabilities, views on the integration of this group of people in their communities, their employment and the place they should occupy in society, the declaration of readiness to help them and to have social leniency towards people with various disabilities.

The juxtaposition and interpretations of the conducted research carried out on representative nationwide groups show that over the last thirty years, the percentage of people who express positive attitudes towards people with disabilities is constantly growing. ${ }^{5}$ Social activities are characterized by an increasing awareness of the life situation of this group of people, although there is still a lack of involvement in personal relationships (familiarity, friendship).

Previous Polish studies ${ }^{6}$ show that these people are perceived through the prism of physical fitness (weak, anxious, insecure, dis-

${ }^{4}$ A. Ostrowska, Niepetnosprawni w społeczeństwie 1993-2013 [Disabled people in society 1993-2013], Warszawa 2015, Wydawnictwo IFiS PAN.

${ }^{5}$ A. Ostrowska, Niepetnosprawni w społeczeństwie 1993-2013 [Disabled people in society 1993-2013], Warszawa 2015, Wydawnictwo IFiS PAN; M.T. Westbrook, V. Legge, M.Pennay, Attitudes towards disabilities in a multicultural society, Social Science \& Medicine, 1993, 36(5): 615-623. DOI.10.1016/0277-9536(93)90058-C.

${ }^{6}$ A. Ostrowska, Badania nad niepetnosprawnościa w Polsce [Research on disability in Poland], Warszawa 1994, Instytut Filozofii i Socjologii PAN. 
satisfied with life, nervous) and issues related to social activity (hidden, suspicious, insecure, dependent on loved ones, poor people). However, the results of the last poll7 show that the respondents still choose such features as: insecure, poor, and other features i.e. anxious, sad, nervous, complaining - ascribing them to the disabled as much as other people in society. In the context of the social mechanisms that have always existed, the stereotypical perception of a person who for some reason is different and a coherent context of different understandings of the problem of otherness, it would be interesting to attempt to look at the relationships that occur between people with disabilities.

The research carried out was aimed at showing how people with physical dysfunction perceive people with other disabilities (intellectual, visual, hearing, and mental illness) and what is the nature of interaction between them. It seems that the fact of experiencing difficulties, which are a consequence of the negative attitude of the social environment, may have significance in dealing with people whose "otherness" is also stigmatized. The analysis carried out will therefore be an attempt to answer the question whether in meetings with individuals with a different type of disability, people with physical disability share a stigmatizing perception and social definition that determines human values and affects the attitude of the interaction. Moreover, it seems interesting to follow the way of dealing with the disability of another person, or in a group of people with mobility problems, because this otherness is approved or negatively evaluated and removed.

\section{Research Methodology}

The respondents participating in my study are a group of 75 people with physical disabilities, who experience various kinds of damage to the locomotive organ, and who have a certificate of disa-

7 A. Ostrowska, Niepetnosprawni w społeczeństwie 1993-2013 [Disabled people in society 1993-2013], Warszawa 2015, Wydawnictwo IFiS PAN. 
bility. The respondents number $55.7 \%$ women and $44.3 \%$ men; their ages are as follows: under 30 years old $-31 \%$, from 30 to 40 years $29.9 \%$, over 40 years $-39.1 \%$; the majority $(56.9 \%)$ are unmarried; nearly half have secondary and post-secondary education (46.6\%) and slightly more than half study or are employed (51.2\%); most reside in small towns (40.2\%); almost $60 \%$ of the respondents were disabled from birth or lost their efficiency before the age of 18. The selection of the group was made on the basis of the availability of respondents. The respondents are people with physical disabilities living in the Mazowieckie voivodship and Warsaw.

The study used the diagnostic survey method and focus group interviews. The obtained results helped to construct the questionnaire, which was used to conduct the quantitative research. The questionnaire contained 45 questions, including 36 closed questions, 9 semi-open questions and 15 survey questions. The research was carried out through the personal access of the researcher to the respondents and the request to complete the questionnaire, which concerned the issue of proximity and social distance to people with a particular type of disability, social preferences, integration activities, responsibility for help and evaluation of people with other types of difficulties.

\section{Research Findings}

The purpose of the interpretations was to determine whether respondents, experiencing psychosocial difficulties resulting from their own disability, take over and share the common attitude and perception towards people with disabilities. Therefore, the first part presenting the results concerns the issue of the universal image of people with disabilities and its importance in the perception of people with other disabilities by people who have physical disabilities. The issues of perception and the social situation of people with disabilities were discussed here. The article also presents the results of the respondents' beliefs about people with a disability other than 
having to do with motor skills. The second part of the analysis captures the respondents' convictions about the need for help and integration measures for people with disabilities. It also includes an attempt to identify trends present in the respondents' relations, which would help to determine whether people with physical disabilities seek to contact individuals with a different type of disability or try to avoid them.

\section{Social Image of People with Disabilities in the Opinion of People with Physical Disability}

In the created image of the social perception of people with disabilities, the elements of loneliness, weakness, social withdrawal and dependence on others are clearly highlighted ${ }^{8}$. Therefore, the respondents were asked - people with motor disabilities - what their opinion is about the features and general opinions defining people with various types of restrictions.

In the organized results, regarding which features are characteristic of a group of people with disabilities, the respondents disagreed with the majority of social opinions about people with disabilities. In particular, many respondents denied that people with various difficulties in functioning are weak, dissatisfied with life or fearful. On the other hand, the respondents agreed with the general assessment that the disabled are easier to hurt than non-disabled people and that these individuals are more often insecure.

The obtained analysis indicate that the respondents confirmed the presence of social schemes that stigmatize the dissimilarity of appearance and functioning with disability. They probably experience negative attitudes of their surroundings and are aware that other people with disabilities are also subject to social ostracism

8 A. Ostrowska, Badania nad niepetnosprawnościa w Polsce [Research on disability in Poland], Warszawa 1994, Instytut Filozofii i Socjologii PAN. 
as marked by the stigma of otherness-alienation. When assessing common opinions about people with disabilities, the respondents did not confirm social thinking patterns concerning the terms related to decision making, quality of life, and sustained the assessments that are related to difficulties in social interactions.

In order to get to know the point of view of people with physical disabilities regarding the specifics of social fear of otherness, which is disability, they were asked what kind of disability society most often avoids contact with. The majority of respondents - almost 75\% - indicated that in their opinion the public is most worried about people who have mental problems. In the second place, they avoid people with intellectual disabilities, and in the third - people with mobility disabilities. Such an assessment coincides with the opinion that, according to research on this subject, the whole of society has, which also avoids, above all, those with mental illness and intellectual disabilities.

The results obtained show that the respondents did not negatively mark the sensory disability group. It seems that people who are blind and deaf, in the opinion of people with physical disabilities, do not arouse the reluctance of society by their presence. The respondents probably recognized that these people more often than other people with disabilities are able to hide their physical ailments, and thus can be treated as non-disabled individuals.

Different types of problems related to the experience of disability, still existing architectural barriers result in people with mobility disabilities to be dependent on the help, support and presence of other people in the immediate vicinity, who are generally ablebodied. However, the social environment in which people with mobility problems live is also created by other disabled people with similar illnesses and people with disabilities different from their own. The surveyed people with physical disabilities, were therefore asked what, in their opinion, the ratio of people with problems with mobility is, to people with different kinds of disabilities.

The surveyed people with physical disabilities were asked what, in their opinion, are the attitudes of people with physical disabilities 
towards people with another type of disability (Chart no. 1). The majority of respondents - $60 \%$ - said that they are very good or good, but $30 \%$ have no opinion on the subject.

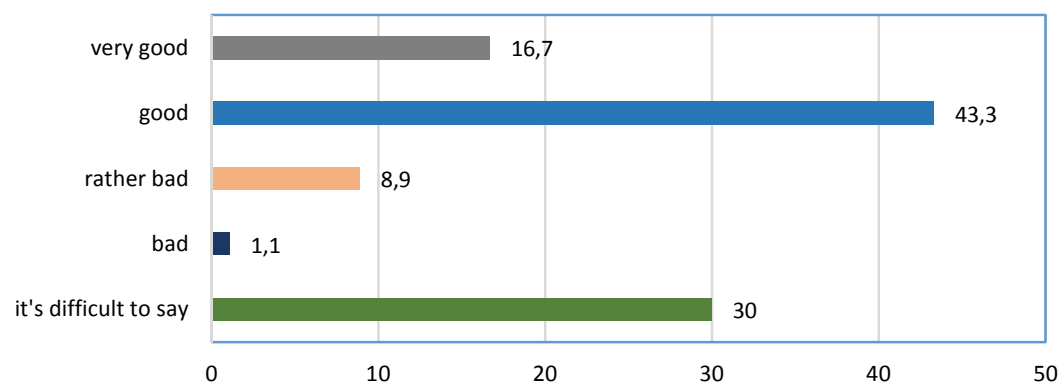

Chart no. 1. Opinion about attitudes of people with physical disabilities towards people with another type of disabilities (in \%)

The aim of the conducted analysis is to determine whether the respondents - people with physical disabilities - themselves experiencing difficulties resulting from limitations and negative perception by the environment, establish unmediated, individual relationships with people with disabilities, or whether they duplicate the social perceptions concerning the image of people with limited mental development, reduced sensory efficiency and other impairments of mental function and mobility. Therefore, the respondents were asked to choose which of the adjectives, given in two groups negative and positive - and which were the most suited to each group of people. Table no. 1 shows the negative adjectives data.

In order to find out whether the image of individuals with disabilities also includes positive opinions of respondents (people with mobility problems) they were asked to rate people with mobility disabilities, intellectual disabilities, visual disabilities, hearing disabilities and mental illness. The obtained data show that the respondents, marking the terms with a pejorative colour, duplicate social patterns and least favourably evaluate individuals with a mental 
Table no. 1. Negative adjectives

\begin{tabular}{|c|c|c|c|c|c|}
\hline $\begin{array}{c}\text { In which groups } \\
\text { people are: }\end{array}$ & $\begin{array}{c}\text { Physical } \\
\text { disabilities }\end{array}$ & $\begin{array}{c}\text { Intellectually } \\
\text { disabilities }\end{array}$ & $\begin{array}{c}\text { Visual } \\
\text { disabilities }\end{array}$ & $\begin{array}{c}\text { Hearing } \\
\text { disabilities }\end{array}$ & $\begin{array}{l}\text { Mental } \\
\text { illnesses }\end{array}$ \\
\hline Apprehensive & $5,6 \%$ & $29,2 \%$ & $6,7 \%$ & $4,5 \%$ & $53,9 \%$ \\
\hline Weak & $24,7 \%$ & $25,8 \%$ & $4,5 \%$ & $2,2 \%$ & $42,7 \%$ \\
\hline Lonely & $13,5 \%$ & $23,6 \%$ & $9 \%$ & $7,9 \%$ & $46,1 \%$ \\
\hline Suspicious & $10,1 \%$ & $13,5 \%$ & $12,4 \%$ & $14,6 \%$ & $49,4 \%$ \\
\hline Unfriendly & $14 \%$ & $17,4 \%$ & $5,8 \%$ & $8,1 \%$ & $54,7 \%$ \\
\hline Quickly withdrawing & $18,2 \%$ & $26,1 \%$ & $8 \%$ & $3,4 \%$ & $44,3 \%$ \\
\hline Helpless & $22,2 \%$ & $28,9 \%$ & $6,7 \%$ & $2,2 \%$ & $40 \%$ \\
\hline Nervous & $17 \%$ & $5,7 \%$ & $4,5 \%$ & $9,1 \%$ & $63,6 \%$ \\
\hline Boring & $11,4 \%$ & $22,7 \%$ & $3,4 \%$ & $29,5 \%$ & $33 \%$ \\
\hline Complainer & $62,5 \%$ & $8 \%$ & $3,4 \%$ & $4,5 \%$ & $21,6 \%$ \\
\hline Self-conscious & $27 \%$ & $14,6 \%$ & $22,5 \%$ & $6,7 \%$ & $29,2 \%$ \\
\hline Dependent & $27,3 \%$ & $27,3 \%$ & $14,8 \%$ & $2,3 \%$ & $28,4 \%$ \\
\hline Bitter & $34,1 \%$ & $12,5 \%$ & $4,5 \%$ & $6,8 \%$ & $42 \%$ \\
\hline Secretive & $16,7 \%$ & $23,3 \%$ & $8,9 \%$ & $15,6 \%$ & $35,6 \%$ \\
\hline Poor & $22,5 \%$ & $29,2 \%$ & $12,4 \%$ & $5,6 \%$ & $30,3 \%$ \\
\hline Malicious & $32,2 \%$ & $9,2 \%$ & $3,4 \%$ & $3,4 \%$ & $51,7 \%$ \\
\hline Uneducated & $9,1 \%$ & $47,7 \%$ & $2,3 \%$ & $3,4 \%$ & $37,5 \%$ \\
\hline Argumentative & $19,8 \%$ & $16,3 \%$ & $9,3 \%$ & $5,8 \%$ & $48,8 \%$ \\
\hline Impatient & $25,8 \%$ & $23,6 \%$ & $5,6 \%$ & $5,6 \%$ & $39,3 \%$ \\
\hline Neglected & $12,8 \%$ & $30,2 \%$ & $9,3 \%$ & $0 \%$ & $47,7 \%$ \\
\hline
\end{tabular}

illness. People with intellectual disabilities were usually second in the negative assessment of people with disabilities. People with sensory disabilities, especially those with hearing disabilities, were rarely chosen.

The respondents also assessed which of the positive definitions best describes each group of individuals with disabilities. The results obtained show that the respondents, by marking adjectives with a positive colour, most often referred to their own group. In the second place, the respondents most often positively assessed 
individuals with visual disabilities. Then the respondents proceeded to indicate people with intellectual disability and people with hearing disabilities. Favourable assessments of people with sensory disabilities duplicate social opinions about this group of people. The most rarely chosen are positive adjectives in relation to individuals with mental illness. The perceptions of those who are physically disabled are consistent with those of general society with regards to people with intellectual disabilities, individuals with sensory disabilities and people with mental health issues. Table no. 2 shows the detailed results about positive adjectives data.

Table no. 2. Positive adjectives

\begin{tabular}{|l|c|c|c|c|c|}
\hline $\begin{array}{c}\text { In which groups } \\
\text { people are: }\end{array}$ & $\begin{array}{c}\text { Physical } \\
\text { disabilitis }\end{array}$ & $\begin{array}{c}\text { Intellectually } \\
\text { disabilities }\end{array}$ & $\begin{array}{c}\text { Visual } \\
\text { disabilities }\end{array}$ & $\begin{array}{c}\text { Hearing } \\
\text { disabilities }\end{array}$ & $\begin{array}{c}\text { Mental } \\
\text { illnesses }\end{array}$ \\
\hline Brave & $61,8 \%$ & $11,2 \%$ & $12,4 \%$ & $6,7 \%$ & $\mathbf{7 , 9} \%$ \\
\hline Strong & $58,4 \%$ & $10,1 \%$ & $16,9 \%$ & $11,2 \%$ & $3,4 \%$ \\
\hline Sociable & $\mathbf{7 5 , 6 \%}$ & $7,8 \%$ & $8,9 \%$ & $4,4 \%$ & $3,3 \%$ \\
\hline Unsuspicious & $31,8 \%$ & $\mathbf{4 0 , 9} \%$ & $14,8 \%$ & $5,7 \%$ & $6,8 \%$ \\
\hline Friendly & $50 \%$ & $\mathbf{2 8 , 9} \%$ & $13,3 \%$ & $4,4 \%$ & $3,3 \%$ \\
\hline Persistent & $61,8 \%$ & $1,1 \%$ & $27 \%$ & $4,5 \%$ & $5,6 \%$ \\
\hline Resourceful & $62,2 \%$ & $4,4 \%$ & $23,3 \%$ & $8,9 \%$ & $1,1 \%$ \\
\hline Calm & $46,7 \%$ & $3,3 \%$ & $\mathbf{3 4 , 4} \%$ & $\mathbf{1 5 , 6 \%}$ & $0 \%$ \\
\hline Interesting & $56,7 \%$ & $8,9 \%$ & $21,1 \%$ & $10 \%$ & $3,3 \%$ \\
\hline Content & $43,3 \%$ & $23,3 \%$ & $14,4 \%$ & $7,8 \%$ & $\mathbf{1 1 , 1 \%}$ \\
\hline Confident & $\mathbf{6 6 , 7} \%$ & $13,3 \%$ & $8,9 \%$ & $6,7 \%$ & $4,4 \%$ \\
\hline Independent & $50 \%$ & $6,7 \%$ & $10 \%$ & $\mathbf{2 7 , 8} \%$ & $5,6 \%$ \\
\hline Happy & $40,4 \%$ & $25,8 \%$ & $14,6 \%$ & $11,2 \%$ & $7,9 \%$ \\
\hline Outgoing & $52,8 \%$ & $25,8 \%$ & $10,1 \%$ & $9 \%$ & $2,2 \%$ \\
\hline Patient & $35,2 \%$ & $9,1 \%$ & $\mathbf{4 5 , 5 \%}$ & $10,2 \%$ & $0 \%$ \\
\hline Wealthy & $49,4 \%$ & $13,8 \%$ & $14,9 \%$ & $14,9 \%$ & $6,9 \%$ \\
\hline Good-hearted & $42 \%$ & $\mathbf{2 6 , 1} \%$ & $17 \%$ & $6,8 \%$ & $\mathbf{8} \%$ \\
\hline Well groomed & $59,3 \%$ & $1,2 \%$ & $16,3 \%$ & $\mathbf{2 0 , 9} \%$ & $2,3 \%$ \\
\hline Educated & $\mathbf{6 3 , 3 \%}$ & $5,6 \%$ & $15,6 \%$ & $11,1 \%$ & $4,4 \%$ \\
\hline Consistent & $40,4 \%$ & $18 \%$ & $\mathbf{3 2 , 6 \%}$ & $9 \%$ & $0 \%$ \\
\hline
\end{tabular}


In the opinion of the respondents, people with physical disabilities often complain (62.5\%), they are bitter (34.1\%) and malicious $(32.2 \%)$. At the same time, in their opinion, it is this group of individuals with disabilities who are social people $(75.6 \%)$, confident $(66.7 \%)$ and educated $(63.3 \%)$. The obtained data show that, most of the respondents with physical disabilities think that intellectually disabled people are: uneducated (47.7\%), neglected $(30.2 \%)$, apprehensive $(29.2 \%)$, and poor $(29.2 \%)$. Respondents also believe that these people are unsuspicious (40.9\%), friendly (28.9\%) and goodhearted $(26.1 \%)$.

In contrast, they think that people with visual disabilities are insecure $(22.5 \%)$, dependent $(14.8 \%)$ and suspicious and poor (by $12.4 \%)$. In addition, respondents perceive these people as patient $(45.5 \%)$, calm $(34.4 \%)$ and consistent $(32.6 \%)$. In the perception of many respondents, people with hearing disabilities are boring $(29.5 \%)$, secretive $(15.6 \%)$ and suspicious $(14.6 \%)$. In the perception of the majority of respondents people with visual disabilities are boring $(29,5 \%)$, secretive $(15,5 \%)$ and suspicious (14,6\%). Among the positive features, the most frequently indicated is that they are independent $(27.8 \%)$, well groomed $(20.9 \%)$ and calm $(15.6 \%)$. Respondents estimated that mentally ill people are nervous $(63.6 \%)$, unfriendly (54.7\%) and fearful (53.9\%). A few questioned indicated a positive determination in relation to this group of people: $11.1 \%$ indicated that they are content, $8 \%$ good-hearted, and $7.9 \%$ that they are courageous.

The opinions of the respondents concurred with that of general society regarding the perception of people with intellectual disabilities, individuals with sensory disabilities and people with mental health problems. In the opinion of the general public, people with visual or hearing disabilities create a kind of closed world that is incomprehensible to the "uninitiated". "The observers from the outside" often state that these people are suspicious, insecure, helpless (that respondents assessed people with visual disabilities in the same way) and boring and secretive (which was the same opinion as the respondents regarding people with hearing disabilities). 
People with sensory disabilities are also perceived more positively than people with other difficulties. These disabilities are less visible and often, according to popular opinion, are associated with having some exceptional, disability-compensating talents. In the schematic thinking of society, people with visual disabilities are distinguished by humility and serenity, therefore they are, as the respondents indicated, patient, self-controlled and unanimous. The perception of people with auditory disabilities, whose deficiencies are completely invisible, is the most positive. This group of people is often considered to be able-bodied, therefore they are perceived, as the respondents indicated, as independent and well-groomed individuals. Whereas, people with mental illness and individuals with intellectual disabilities are particularly negatively perceived. Society is afraid of people who, due to various types of mental disorders, do not behave in a predictable and rational manner. They are usually perceived by society, whose views are similar to those of the respondents, as nervous and unfriendly people. Moreover, the obtained data shows that few respondents marked positive adjectives for this group of people.

In a society where the highest values include effective use of reason, accuracy and speed of decision making, calculations of profits and start-up as well as resourcefulness, a reduction of mental ability is treated as a particularly undesirable limitation. People with intellectual disabilities are therefore perceived, as the respondents indicated, as uneducated, neglected, fearful and poor. Regardless of this, individuals with intellectual disabilities are often called "big children" and in the common opinion they also function as trustworthy, friendly and kind-hearted people.

Analysis of the data show that the respondents, when assessing people with a disability other than their own, take over and reinforce social schematic assessments, and partly reject the prevailing opinions about people with mobility disabilities. In the group's own assessment, the respondents, on the one hand, admitted that people with mobility disabilities often complain, are bitter and mean, and 
on the other hand, they have ennobledly indicated that they are sociable, confident and educated. In addition, the majority of respondents had positive adjectives for this group. Opinions of the general public ${ }^{9}$ are more generalized, focused on differences in appearance and limited possibilities.

\section{Integrative versus Separate Social Orientations of People with Physical Disability towards People with the Other Kinds of Disability}

The aim of the conducted research was to obtain information on what relations between people with mobility disabilities and people with a different type of disability looks like. Conducted analysis will be aimed determining whether the personal experience of negative treatment of disabled people induces respondents to a deeper, more authentic dimension of an encounter with another human being, regardless of its otherness or whether it causes taking over and duplicating social automatism of classification and imposing identity. People experiencing various types of physical and mental disabilities need care, help and support in everyday matters. Respondents were asked, therefore, who they think should take care of it and what their position is in relation to the currently functioning integration processes.

For more information about who is responsible for the help people with disabilities should receive, respondents were asked to rank their opinion: 1 - most need help, 2 - as the second in the sequence should help etc. until 6 or 7 . The data represent the mean of elected answers and show to what extent the respondents indicated for responsibility for helping in a particular group. For the six groups $(\mathrm{a}, \mathrm{b}, \mathrm{c}, \mathrm{d}, \mathrm{e}, \mathrm{f})$ The lower that the number is, correlates to a higher level of perceived responsibility.

${ }^{9}$ A. Ostrowska, Badania nad niepetnosprawnościa w Polsce [Research on disability in Poland], Warszawa 1994, Instytut Filozofii i Socjologii PAN. 


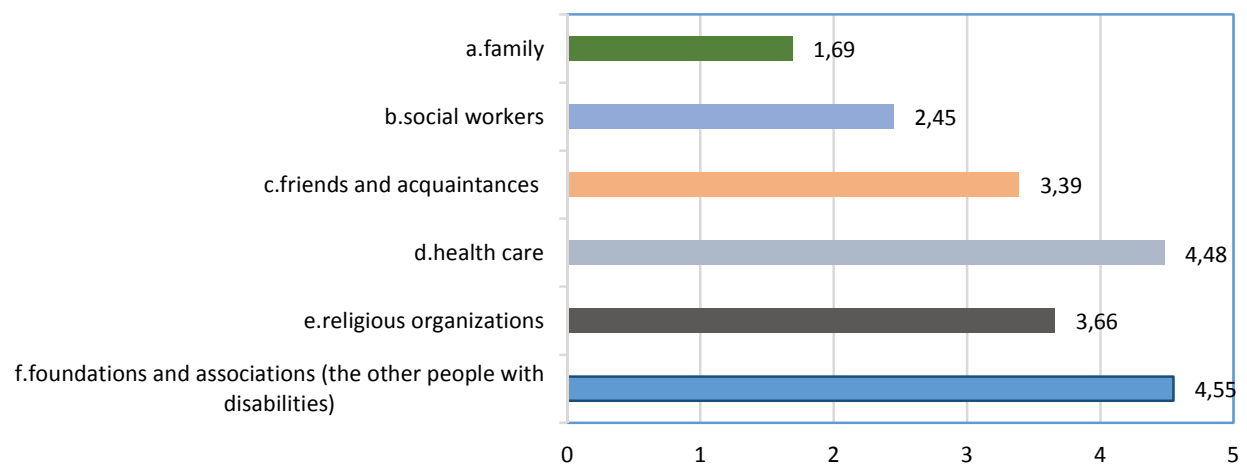

Chart no. 2. Responsibility for helping people with disabilities

Calculations show that most of those questioned ranked family in the first place (the mean of the response - 1.69). They considered, therefore, that help for people with disabilities should be provided primarily by relatives. Second, it is estimated that social workers should help (the mean of the response -2.45). Similarly, it was indicated that health care should provide help to individuals with all sorts of problems in functioning, and friends and acquaintances (mean of the answers - 4.48 and 3.39). Least often they stated that assistance should be provided by religious organizations and by other people with disabilities who work in foundations and associations (mean respectively -3.66 and 4.55 ). This data is shown in Chart no 2.

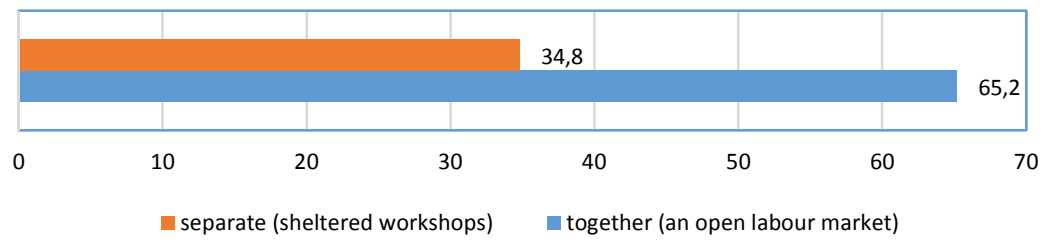

Chart no. 3. Separate or integrative forms of employment for people with disabilities (in \%) 
In order to determine the opinions of respondents on social inclusion, I asked if able-bodied people and physically disabled people and those with another type of disability should be together or separate in places such as the workplace, residential areas, schools or trips.

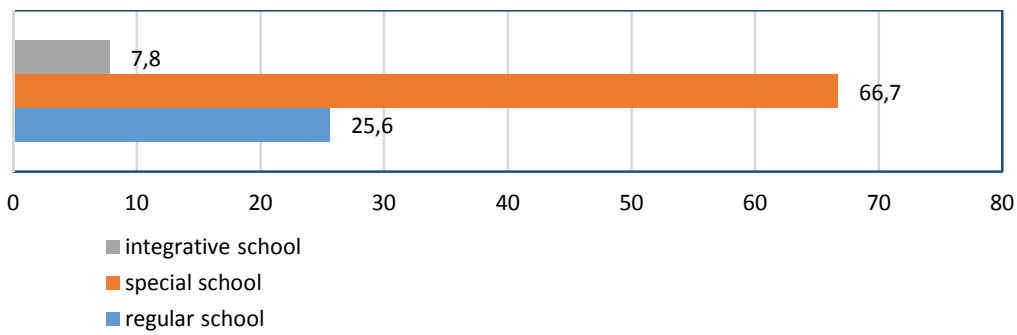

Chart no 4. Separate or integrative forms of schooling (in \%)

The data obtained about the workplace show (Chart no. 3) that the majority of respondents are in favour of an integrative form of employment for people with disabilities - $65.2 \%$ of those interviewed. Answers expressing their opinions on how people should be educated, again show (Chart no. 4) that the majority of respondents, $66.7 \%$, are in favour of integration. But some of those interviewed also believe otherwise: $25.6 \%$ - and said that the best schools are regular, and $7.8 \%$ - believe that individuals with a disability should attend special schools.

The aim of the study was also to determine the opinion of respondents on the matter of integration solutions in the construction of residential buildings. The results shows Chart no. 5 .

The majority of respondents $-57.3 \%$ - considers that it is necessary to build settlements where people can live with all different types of disabilities with non-disabled people. While some of them would prefer housing estates that were built only for people with 
physical disabilities and able-bodied individuals - thus marked $29.2 \%$ of the group. Among the respondents, there are also those who think that it would be best to build separate settlements for people with disabilities and their families and to adapt them to different types of disability (13.5\%).

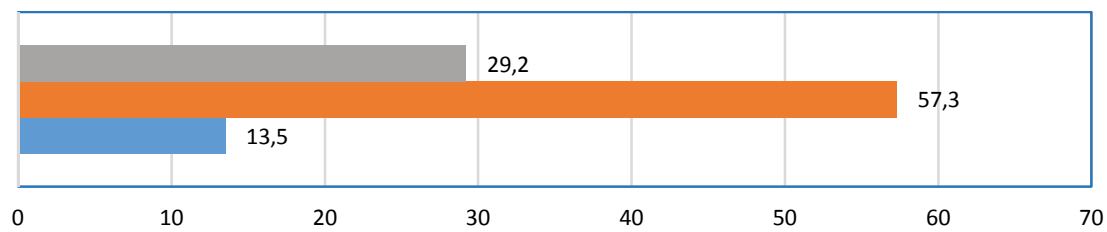

to built only for people with physical disabilities and able-bodied individuals

to build estate where people can live with all different types of disabilities with non-disabled people

to build separate estare for people with disabilities and their families and to adapt them to different types of disability

Chart no. 5. Integration solutions in the construction residential buildings (in \%)

The respondents were also asked how to organize the meetings of different groups of people - able-bodied and disabled - on trips and recreational meetings in all sorts of clubs, community centres, etc.. The results show (Chart no. 6) that in the opinion of many respondents it is best when people with physical disabilities, people with another type of disability, and able-bodied jointly participate in all kinds of trips, events, meetings. $72.4 \%$ of the group marked in this way. Nearly $20 \%$ of respondents said that it is best when persons with different types of disabilities belong to the same clubs, community centres, and together they participate in common trips. Only $8 \%$ believe that it is better to organize separate trips, clubs, etc. for people with different kinds of disability. 
Trips and recreational meetings in all sorts of clubs, community centers, etc

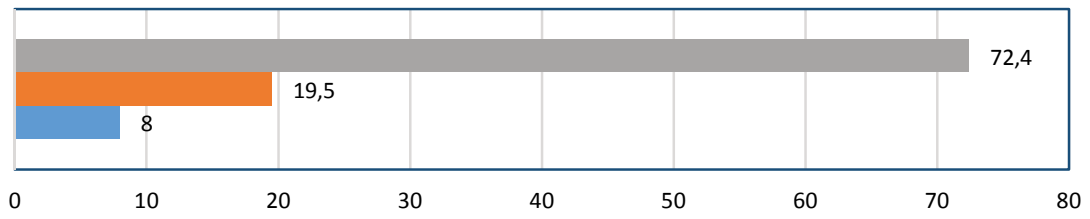

the best is when people with physical disabilities, people with another type of disability, and able-bodied jointly participate in all kinds of trips, events, meetings

the best is when persons with different type of disabilities belong to the same clubs, community centers, and together they participate in common trips

it is better to organize separate trips, clubs, etc. for people with different kinds of disability

Chart no. 6. Organisation of meetings of different groups of people (in \%)

The respondents were also asked about their willingness to help people with another type of disability. The results of the survey show (Chart no. 7) that the majority of respondents - $64.4 \%$ - said that if a person with a different disability lived in their neighbourhood, they would willingly help him/her in everyday life matters. Some of the interviewed $-16.7 \%$ - said they "would rather" help. Almost no one would refuse to assist (only 1.1\%), and 5.6\% said they "probably" would not help. Among the respondents $12.2 \%$ of those interviewed had no opinion on this matter.

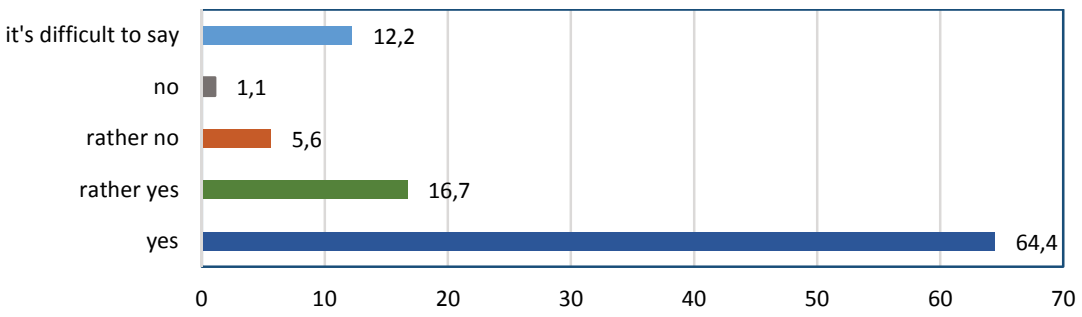

Chart no. 7. Personally helping disabled people (in \%)

Seeking to discover if those opinions are the result of interpersonal experiences, or just conjecture, I asked about the frequency of 
contact with respondents in those particular groups. The results show the surveyed person's proximity/intimacy and social distance towards people with intellectual disabilities, individuals with visual disabilities, people with hearing disabilities, persons with mental illness and people with physical disabilities. The obtained results are shown in Chart no. 8.

My results show that most questioned have relationships with people who have a similar type of disability. It turns out that more than half have or had such a person among their acquaintances, and $34.8 \%$ in the family and among close friends. The respondents meet or met also with individuals with sensory disabilities. Almost $40 \%$ count a person with visual disabilities as a friend, and almost $30 \%$ know one not so well or only by sight.

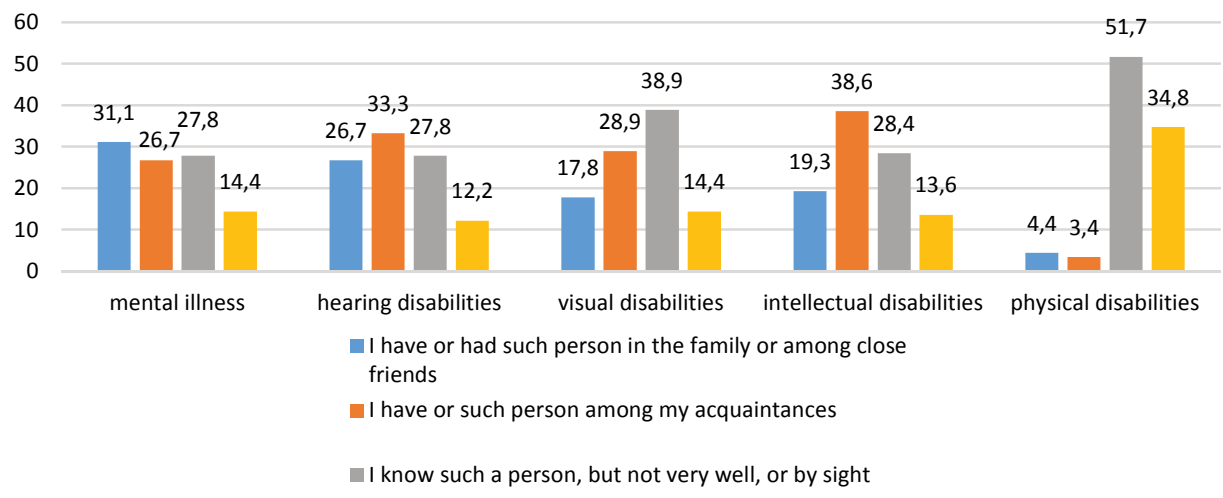

Chart no. 8. Contact of respondents with people with particular group of people with disability (in \%)

Less often respondents meet or met with people with intellectual disabilities. Almost $40 \%$ are not very familiar with such persons or know them only by sight. Slightly fewer questioned - $28.4 \%$ think about individuals with intellectual disabilities as a friend. However, $19.3 \%$ of respondents have a complete lack of contact 
with this group. As my results showed, respondents have the most limited contact with individuals with mental illness. Over 30\% do not know such people. Most of the other respondents, with similar frequency, emphasized that they have such people among their friends $(27.8 \%)$ and that they know such a person, but not very well, or by sight $(26.7 \%)$.

In addition, to determine what are the general social preferences of the respondents, they were asked, which of these groups they spend the most time with (including able bodied). The majority of respondents $-64.4 \%$ - have friends who are non-disabled. Some of those interviewed $-27.8 \%$ - stated that some of their friends have physical disabilities, and $7.8 \%$ said they are friends with individuals with disabilities other than physical. The obtained results are shown in Chart no. 9.

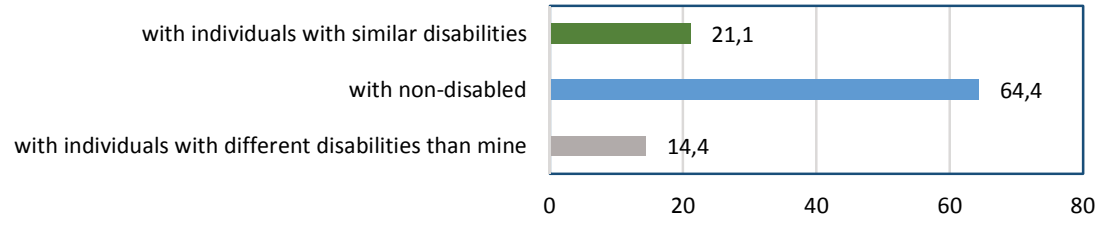

Chart No. 9. Spending time with people from all groups (including able-bodied) (in \%)

\section{Social Preferences of People with Physical Disability Regarding Other Disabled People}

In order to gain knowledge about the choice of social relations of people with physical disabilities, respondents were asked which groups of disabled people they would be unwilling to have various types of social interaction with. The results are shown in Chart no. 10.

It turns out that in response to all the questions asked, respondents most often admitted that they would not enter into relationships with people with mental illness. The largest number of respondents indicated in this way with regard to possible neigh- 
bourhood (75.6\%), friendship (70\%) and choice of partner / life partner $(68.9 \%)$. It can therefore be concluded that the respondents particularly do not want to deal with this group of people in their immediate environment and in their personal relationships.

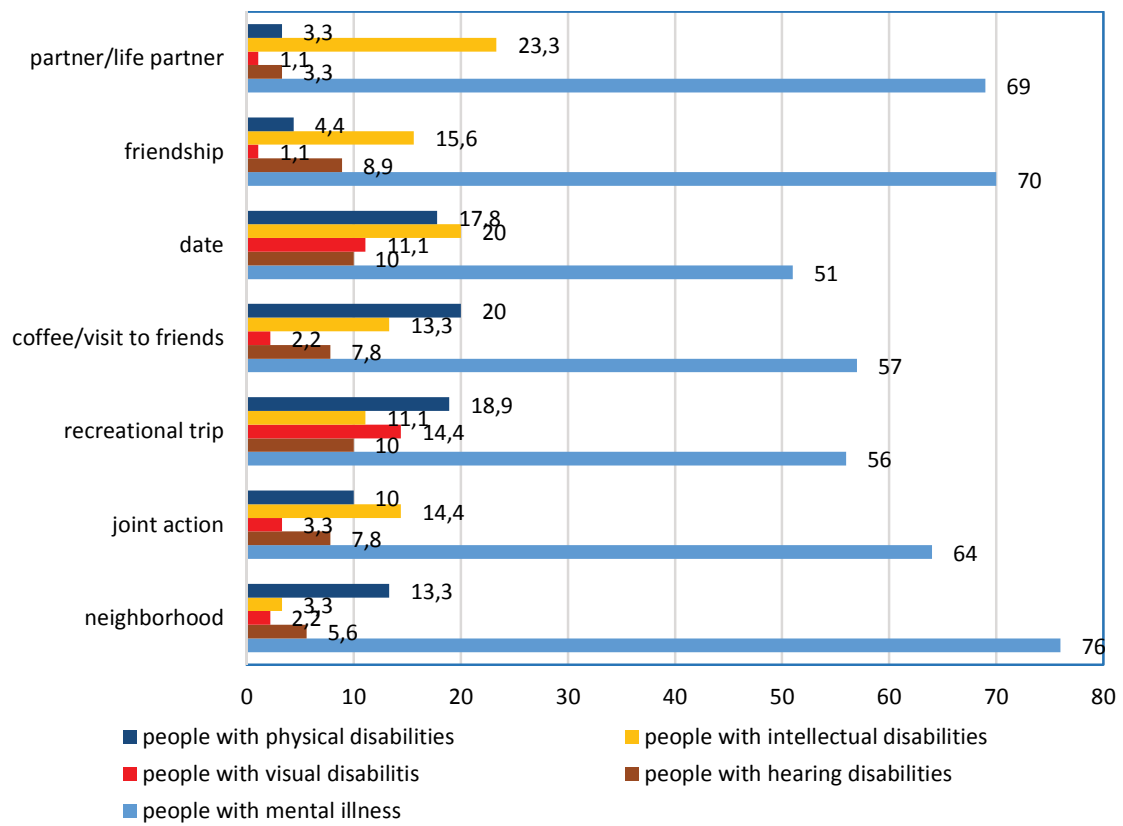

Chart no. 10. Frequency of choosing groups of people with disabilities, with whom the respondents would be unwilling to have social interactions (in \%)

Similarly, people with intellectual disabilities are also not accepted in the closest contact (partner/life partner $-23.3 \%$, date $-20 \%$, friendship $-15.6 \%$ ), but are, by the vast majority of the respondents, welcome as neighbours. Some of the respondents do not want to keep in touch with their own group in social relations: coffee/visit to friends $-20 \%$, recreational trip $-18.9 \%$, date $-17.8 \%$. Many respondents do not mind friendship, creating a relationship or neighbourhood relation with people with similar difficulties in functioning 
(negative answers were indicated by only $4 \%$ of those who were asked). Few respondents are opposed to making different types of interactions with people with hearing disabilities. The subjects to which such relationships interfere, indicated answers related to social life: a date and a recreational trip - 10\%, friendship - 8.9\%. Only 3.3\% would not like to be with a partner in this group of people with disabilities. The respondents are least at odds with relationships with individuals with visual disabilities. This group of people was the least often indicated in relation to the closest contacts - the answer "no" was indicated by only about $1 \%$ of the respondents.

The obtained results indicate a definite choice of people with a physical disability by the respondents in all closer and further relations. Most of the respondents want to be with people with a similar type of difficulty in functioning in friendship and in joint action (85.2\% and $79.8 \%$ respectively). Other groups of people with disabilities were less frequently marked (Chart no. 11).

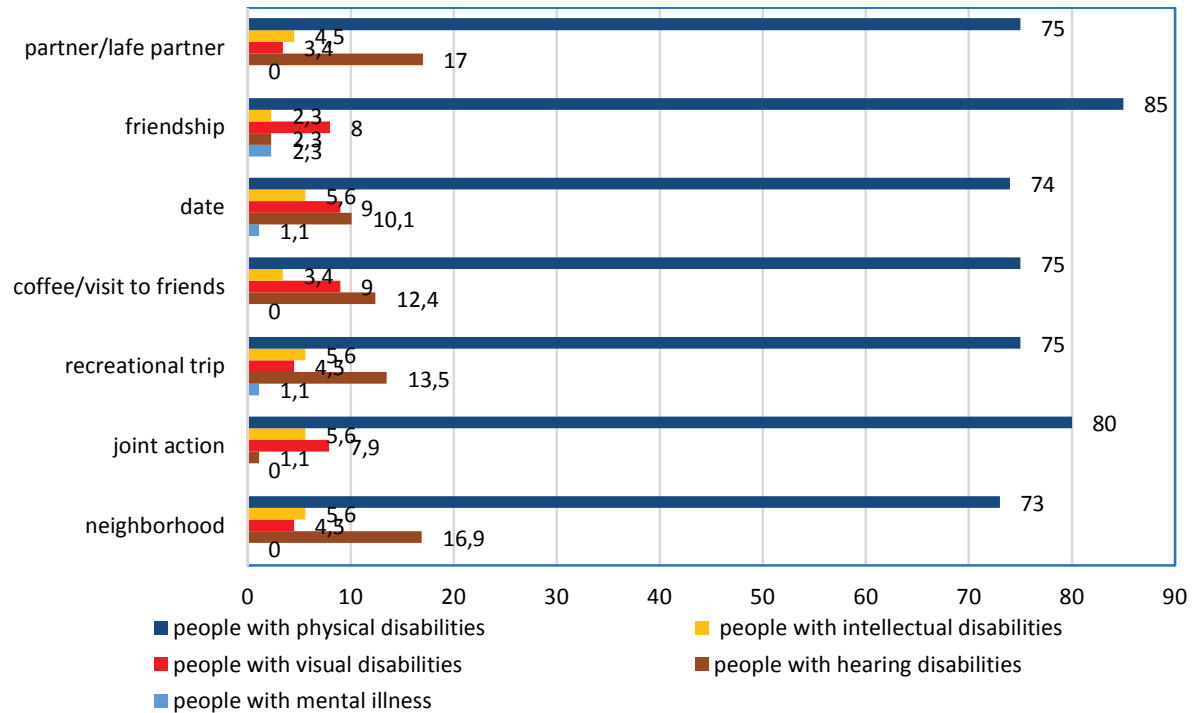

Chart no. 11. Frequency of choosing groups of people with disabilities, with whom they would willing enter into relationships (in \%) 
People with hearing disabilities are the second group in the order with which, according to the obtained research results, the respondents most often want to enter into relationships. A relatively large number of respondents indicated that they would be willing to be in a relationship with such a person or have them as a neighbour. There was less willingness to have interactions such as friendship or joint action. Those with visual disability were most often chosen in interactions regarding social life and cooperation (coffee or a visit to friends), and less often when it was about establishing an intimate relationship. The least often indicated by the respondents, and therefore least accepted in the relations, are people with mental illness.

\section{Conclusion and discussion}

The obtained data allows us to state that it is primarily ablebodied people who are the reference group for the surveyed people. With the able-bodied people, most of the respondents want to stay, live, cooperate, contain the deepest relationships, although, as the results indicate, these meetings are not always satisfactory for the respondents. It can therefore be concluded that those with disabilities who are most often surrounded by the respondents are probably also a source of their frustration and difficulties in interpersonal relations. In addition, it also turns out that the respondents know, apart from the able-bodied, above all people with mobility problems. With this group of people, they want to enter into all kinds of relationships and it is the only group among people with disabilities in which they look for friends and partners. The most popular positive terms in relation to people with physical disabilities can confirm that the contacts of the respondents are limited to this group only.

In the literature, we can find confirmation of the results we obtained, where the authors point to the incitement mechanisms be- 
tween the groups. Meeres and Grant ${ }^{10}$ note that through the process of differentiation, whereby 'an individual portrays his or her own group (the in-group) as superior to a relevant other group (the outgroup)', a more positive social identity will be created. The 'ownership' of a disability identity seems to be stimulated by two main motivators; first, the pride in identifying as a member of a minority group in a manner similar to other oppressed groups and, secondly, to restrict the number of competing groups for limited financial resources. On the other hand, the results of the study conducted by Watson ${ }^{11}$ indicate many disabled persons do not see themselves as disabled and do not identify as disabled people. This means that they can see the lack of efficiency and difficulties resulting from it affecting people with different types of disability.

Less positive opinions about people with a different type of disability may result from the objective impossibility of establishing contact or a lack of willingness to meet another person who is also burdened. Negative assessments of the group of people with intellectual disabilities and, above all, individuals with mental illness, duplicate negative attitudes and social stereotypes, and confirm that the lack of direct contact makes it difficult to verify the negative valuation and reduce the distance in the relationships. More positive opinions about people with sensory disabilities, on the one hand, may also be due to a beneficial, social image of these groups, and on the other hand - a desire to interact with people whose disability is less visible. Deal ${ }^{12}$ in his work confirms discriminatory practices and strategies that include focusing attention on those who have impairments and face discrimination in society (i.e. those

10 S.L. Meeres, P.R. Grant, Enhancing collective and personal self-esteem through differentiation: further exploration of Hinkle $\mathcal{E}$ Brown's taxonomy, British Journal of Social Psychology, 1999, 38, pp. 21-34.

${ }^{11} \mathrm{~K}$. Watson, Well, I Know this is Going to Sound Very Strange to You, but I Don't See Myself as a Disabled Person: Identity and disability, 2002, Disability \& Society, Volume 17(5), pp. 509-527.

12 M. Deal, Disabled people's attitudes toward other impairment groups: a hierarchy of impairments, Disability \& Society, 2003, 18: 7, pp. 897-910. 
ranked lowest in the hierarchy of impairments) and disabled people, however, it is important that these discriminatory practices and strategies are addressed to further the common cause in seeking equality within society.

The obtained data leads to a similar conclusion that the most important factor in the perception and treatment of people with disabilities by the respondents has a social impact factor. The preferences and assessments of the respondents coincide with the common opinions on particular groups. The circumstance of a nonreflective deprivation of the social environment is more significant for relations with other people with disabilities than the frequency of contacts and similar difficulties related to the disability experienced.

\section{Bibliography}

[1] Chubon R., An analysis of research dealing with the attitudes of professionals toward disability. Journal of Rehabilitation, 1982, 48(1), pp. 25-30.

[2] Deal M., Disabled people's attitudes toward other impairment groups: a hierarchy of impairments, 2010, Disability \& Society, Vol. 18, No. 7, December 2003, pp. 897-910.

[3] Gething L., Generality vs. specificity of attitudes towards people with disabilities, British Journal of Medical Psychology, 1991, 64, pp. 55-64

[4] Goffman E., Stigma: Notes on Management of Spoiled Identity. Englewood Cliffs, New Jersey 1963.

[5] Hosod M., Stone-Romero E., Coats G., The effects of physical attractiveness on jobrelated outcomes: a meta-analysis of experimental studies. Personnel Psychology, 2006, Vol. 56, Issue 2, 431-462.

[6] MacLaughlin M.E., Bell M.P., Stringer D.Y., Stigma and Acceptance of Persons With Disabilities. Group \& Organization Management, 2004, Vol. 29 No. 3, pp. 302-333

[7] Meeres S.L., Grant P.R., Enhancing collective and personal self-esteem through differentiation: further exploration of Hinkle \& Brown's taxonomy, British Journal of Social Psychology, 1999, 38, pp. 21-34.

[8] Ostrowska A., Badania nad niepetnosprawnościa w Polsce [Research on disability in Poland], Instytut Filozofii i Socjologii PAN, Warszawa 1994.

[9] Ostrowska A., Niepetnosprawni w społeczeństwie 1993-2013 [Disabled people in society 1993-2013], Wydawnictwo IFiS PAN, Warszawa 2015. 
[10] Schilder P., The Image and Appearance of the Human Body. Kegan Paul, Trench, Trubner, London 1935.

[11] Shears L.M., Jensema C.J., Social acceptability of anomalous persons, "Exceptional Children" 1969, vol. 36, pp. 91-96.

[12] Umberson D., Hughes M., The Impact of Physical Attractiveness on Achievement and Psychological Well-Being, Social Psychology Quarterly, 1987, Vol. 50, No. 3, pp. 227-236.

[13] Watson K., Well, I Know this is Going to Sound Very Strange to You, but I Don't See Myself as a Disabled Person: Identity and disability, 2002, Disability \& Society, Volume 17(5), pp. 509-527.

[14] Westbrook M.T., Legge V., Pennay M., Attitudes towards disabilities in a multicultural society, Social Science \& Medicine, 1993, 36(5), pp. 615-623.

[15] Wright B.A., Developing constructive views of life with a disability. Rehabilitation Literature, 1980, 41(11-12), pp. 274-279. 